\title{
Integrating Mobile Culture into Computing Education
}

\author{
Stan Kurkovsky \\ Central Connecticut State University, kurkovskysta@ccsu.edu
}

\begin{abstract}
The term 'mobile culture' describes the evergrowing influence that mobile devices, media and communication have on our day-to-day activities. Current generation of young people is often considered as one of the primary forces helping sustain the evolution of mobile technology, because young people represent a very substantial portion of early adopters and active users of mobile devices, applications, and games. For most college students, electronic gadgets and computer games have always been an integral part of their lives. Consequently, they may perceive mobile devices as true exemplars of the current technology, instead of the desktops that dominate most computer labs. This paper attempts to illustrate the reasons and the possibility of using mobile devices and mobile game development as a learning context and a motivational tool in the computing curriculum.
\end{abstract}

Index Terms - Mobile culture, Mobile games, Motivation, Student learning.

\section{INTRODUCTION}

A phenomenal popularity of mobile devices and the everincreasing role that they play in our everyday lives is often referred to using the term 'mobile culture'. The increasing importance of the user mobility and the availability of anytime anywhere network access has helped create an entirely new set of practices and social norms shared by the vast population of mobile users [8]. Mobile phones not only enable anytime anywhere communication, but they have also extended their capabilities to help users consume and generate a broad range of different kinds of media, which, consequently, has dramatically increased the social significance of these devices.

Young people of the traditional college and high school age have grown up surrounded by gadgets, such as handheld electronic games, media players, and mobile phones, and are literally immersed in mobile culture. Both anecdotal and research evidence indicates that many young people would find it nearly impossible to live a single day without their mobile phones - they would be unable to make phone calls, send text messages, check email, and play games. For a long time, there has been a clear trend of convergence for mobile device features. Today a single device could combine the features of a media player, photo and video camera, navigation device, electronic book reader, and, last but not least, a communication device. As perceived by many young people, they associate the computing technology with these small and ubiquitous devices instead of larger desktops that still dominate most computing laboratories and classrooms. There could be an excellent opportunity to turn young people's love of mobile gadgets from what could become a waste of time into a motivational tool that could foster their interest in computing.

This paper discusses the connections between mobile culture and computing and presents the case for using mobile computing as a learning context to motivate and sustain student interest in computing. We discuss the different ways in which mobile media, gadgets, and mobile games influence the current popular culture, as well as their impact on typical college and high school students.

\section{Computing, as Seen By The Students}

The precipitous drop in enrollments to computing programs has been caused by a combination of many factors. Decreased appeal of computing as a field of study and/or a future career has often been cited as having a higher significance than other factors [9,10,12,14,15]. Many students majoring in computing often decide to change their program of study after taking one or two introductory computing courses. This could happen because they often view the problems and examples presented in such courses as completely irrelevant to the real-world applications of computing $[2,18]$. Students should see that computing curriculum follows the general trend of technological evolution, which can be achieved by demonstrating strong connections between computing and the everyday lives of each student. Mobile computing and mobile game development may have the potential to make such a connection in the form that can be appreciated by young people.

Current high school and college students may see a significant gap between the ways in which they use modern computing technology and how it is currently used in the academic environment. Current retention and recruitment efforts focus on high school and college students, who most likely have had an electronic game or console, or a mobile phone as the first computing device they ever used. It is important to point out that during the fourth quarter of 2010 , for the first time ever the number of smartphones shipped by the manufacturers (which does not include regular mobile phones, tablet computers, etc.) exceeded the number of 
shipped PCs [1]. An IBM study from October 2008 indicates that over a half of consumers surveyed in the US, UK and China prefer to access the Internet with their mobile devices rather than using their PCs [11]. According to this study, respondents between 15 and 30 years of age were the overwhelming majority among those who planned to replace a PC with a mobile device.

Existing popular culture may not form a particularly positive perception of computing as a field of study or work $[5,6,7]$. In order to change this view, computing programs need to stay relevant to students who should see that the academic environment is changing and is keeping up with the evolution of the 'real world.' Students also expect their teachers to be knowledgeable about the current technology. Integrating mobile devices, such as smartphones and tablet computers, in the learning experience may help students perceive the academic program as more up to date and relevant to their experiences and expectations. With few exceptions, students have their mobile phones with them at all times. If they could design, code, deploy and execute a program on their phone, this might provide them with an experience that would be as close to a real-world scenario as it ever gets.

\section{Mobile Culture AND Young PEOPle}

The term 'mobile culture' describes an increasingly important role and the impact that mobile devices, mobile communication, and mobile media have on our day-to-day lives, which ranges from personal interaction to social networking, from grocery shopping to banking, from popular culture to politics. In some languages, special new terms have emerged to describe the mobile phone, which demonstrates the prominent role these devices play, especially in those countries where mobile technology has reached higher degrees of saturation. Specific words referring to a mobile phone include keitai denwa, or simply keitai (something you carry with you) in Japanese, sho ji (hand machine) in Chinese, and kännykkä (an extension of the hand) in Finnish.

A wide variety of mobile interactions are now an integral part of maintaining practically any social relationship. Many top-level and even local election races in the US and elsewhere now incorporate outreach to the voters via Facebook and Twitter. Such interactions are vital for the candidates to help them maintain a connection with the voters by frequently posting updates on social networks. It is increasingly important for the candidate's supporters to have access to these tidbits in real time to stay abreast of their current activities. Many researchers and analysts point out that such near real-time communications available anytime and anywhere via a mobile device help maintain stronger ties among the members of many online social groups, not limited to elected officials and their electorate.

In many ways, modern media culture is shaped by the users who not only consume, but also produce various kinds of media on their mobile devices. Wide availability of camera phones enables many eyewitnesses of breaking news to upload pictures and videos of events as they happen. In many cases, live footage shot on a mobile phone by a bystander may become the only documental evidence of an important event, which is later broadcast on television, posted on the Internet, and discussed in blogs.

Mobile devices have become an extension of media distribution channels and broadcast platforms enabling users stream or download music and video straight to their devices. They have also become a facilitator of fan culture with users being able to download screens and ringtones helping them associate with a particular artist or popular culture phenomenon. Furthermore, mobile interaction has been incorporated into the structure of many television programs. For example, such TV shows as American Idol and Big Brother allow viewers to vote for contestants by sending text messages, while other shows may allow the viewers to play along with the contestants in real time as the TV show airs.

'Mobile culture' and 'mobile media' are two related, but distinct concepts. Mobile media is not a new phenomenon. In fact, one might argue that newspapers and books are mobile media since they can be read anytime and anywhere. More versatile mobile media platforms would include different types of portable computing devices from portable computers to smart phones. The strict technological boundary that once separated laptops from mobile phones is vanishing. Over last three to five years, netbook computers designed primarily for email and web-based applications, have become very popular. A relatively old idea of tablet computers has been revitalized by the exceedingly popular Apple iPad, which has made a substantial impact to further decrease the sales of desktop and laptop computers. To counter this trend, Intel is currently set to roll out a new line of processors designed specifically for ultrabooks, very lightweight notebooks with highly integrated CPUs, solid state storage, and unibody chassis. A broad spectrum of these devices provides the users with different degrees of mobility. Smartphones have the smallest form factor, which is combined with the features for consuming (web browsing, gaming) and producing (taking pictures, recording audio and video) rich media along with anyplace anytime network access. This set of smartphone features has turned out to be the real winner and allowed these devices to gain such an extreme popularity.

Technical convergence and content convergence are both leveraged by mobile devices in a very significant way. The concept of technical convergence refers to the digital nature of media, which could be accessible via different kinds of technological platforms. For example, it is possible to read a newspaper of watch a TV program online using a mobile phone, a tablet computer, or a PC. The concept of content convergence refers to the availability of identical or similar content via different distribution channels and in different media forms, which is frequently used for brand marketing. For example, information related to the most recent "Transformers" movie and its characters could be offered through many different media and non-media 
channels during the same period of time. This may include dedicated websites with videos, stills, desktop backgrounds, screensavers, and ringtones, along with wall posters, blankets and bed sheets, and toys in happy meals. Both content and technical media convergence are primarily aimed at young people and are very effective at exploiting the role that mobile devices play in their lives. Consequently, it is possible to see that it is not just the popular culture that is influenced by the consumer mobility, but it is also that in many ways the popular culture enables and reinforces the role that mobile devices play in the life of the young generation.

Mobile phones are adding a new mobility dimension to the ever-changing landscape of social interaction [19]. High school and college students represent a very significant percentage of the mobile phone users. Many researchers and analysts believe that young people are the primary driving force in the adoption of mobile technology [17]. For young users, mobile phones may serve far beyond the traditional ways of making calls and texting. Many researchers emphasize the symbolic value of a mobile device, which may reflect the style and identity of a young person [13]. In the eyes of their peers, it may be very important to have a full address book on the 'right' brand of phone and receive a continuous stream of text messages. Having grown up with a mobile phone, many high school and college students may often find it as an item that helps determine their identity.

Regardless of their ethnicity, nationality, or cultural background, young people seem to be equally interested in playing games on their mobile devices. Although this may be contributed to the 'westernization' of the entire society, Internet access and mobile devices are viewed by many young people throughout he world as a "nice thing to have". An international survey of nearly 500 young people 18-25 tears of age in the US, Spain and Czech Republic [16] found that the ubiquity of mobile devices had a greater effect on the adoption of mobile games than the perceived fun: young people prefer the convenience to play a game anytime and anywhere using a small device that they carry around with them at all times.

Mobile gaming has become a very popular activity and it is set to hold its ground as an increasing number of young people are considering making mobile devices their primary computing platform. Most mobile games can be played anytime anywhere and, unlike many games for PCs or game consoles, mobile games typically do not require any skills or time commitment.

ACM Computing Curricula recommends using mobile computing as a possible context for teaching computing concepts. Mobile computing and mobile game development could be both highly motivational and technically challenging. Some critics believe that computer games are unappealing for female students because of in-game violence. At the same time, the majority of games played on mobile devices are casual games that have simple rules and require no time commitment. Many studies indicate that an equal percentage of males and females play mobile games

$/ 10 / \$ 25.00$ C2012 IEEE and that female users actually spend more time than males playing games on their mobile phones.

\section{Discussion}

We believe that it is possible to integrate mobile game development into the computing curriculum [12]. In doing so, it is important to also make the connections to many advanced curricular topics as early as possible. Current studies suggest that students frequently become disillusioned in computing because they are presented with too many examples that they perceive as contrived or irrelevant, boring or having very little to do with the real-world applications of computing [2,4]. A certain percentage of students may also be interested in the areas of computing that primarily focus on theory or design instead of coding. Demonstrating a broad variety of advanced topics early in the curriculum in a familiar context of mobile computing could convince students that computing is much more than just coding.

Current research also indicates that more participatory learning methods such as those used in mobile computing and mobile game development could help level the playing field for different types of students [3]. Historically, computing and engineering have been less accessible for female and underrepresented minority students. Using a learning context that values cooperation, interactivity, and collaboration may help female and minority students feel more comfortable. In fact, a number of studies suggest that such learning methods offer a better fit for the learning styles of minority and female students [20].

It is important to balance the educational and motivational aspects of mobile computing by properly combining the material that students would find interesting and help them grow academically. Furthermore, developing playable games is a complex task that typically requires knowledge and skills from different areas of the computing curriculum, such as AI or databases. However, many students with reasonable programming skills are capable of developing a playable casual mobile game within one semester. Additionally, such projects can be used to expose students in introductory courses to a variety of advanced topics needed to develop the game. These projects can provide students with a highly interactive and hands-on experience, allowing them to immediately see the results of their work on their own mobile phone. At the same time, such projects would be easy to adopt because there will be no associated hardware costs since students can test their work on mobile phones they already own.

\section{Conclusion}

Typically, students find it easy to relate to mobile computing and mobile applications, because of the increasingly important role that mobile technology plays in their lives. For many young people, a mobile phone is taking the place of a desktop computer as the embodiment of the modern computing and communication technology. Mobile applications and, in particular, mobile games offer a kind of

March 9, 2012, Ewing, NJ

Integrated STEM Education Conference 
instant gratification when students can download them to their mobile devices and show them off to their friends.

Regardless of how we feel about it, mobile culture is an integral part of our students' lives. Young people will continue carrying their mobile phones with them at all times and they will continue using them to play games. It is our choice as educators whether to use this sometimes distracting technology for the benefit of computing education.

\section{REFERENCES}

[1] Albanesius, C. "Smartphone Shipments Surpass PCs for First Time. What's Next?" PC Magazine, February 8, 2011, http://www.pcmag.com/article2/0,2817,2379665,00.asp.

[2] Beaubouef, T. Mason, J. "Why the high attrition rate for computer science students: some thoughts and observations," SIGCSE Bull. 37, 2 (June 2005), 103-106.

[3] Belenky, M.F., Clinchy, B.M., Goldberger, N. \& Tarule, and J. M. 1986. Women's Ways of Knowing: The Development of Self, Voice, and Mind. New York: Basic Books.

[4] Biggers, M., Brauer, A. and Yilmaz, T. 2008. Student Perceptions of Computer Science: A Retention Study Comparing Graduating Seniors vs. CS Leavers", Proceedings of the 39th SIGCSE Technical Symposium on Computer Science Education, Portland, Oregon, pp. 402-406.

[5] Carter, L. "Why students with an apparent aptitude for computer science don't choose to major in computer science," SIGCSE Bull. 38, 1 (March 2006), 27-31.

[6] Forte, A.; Guzdial, M. "Motivation and nonmajors in computer science: identifying discrete audiences for introductory courses," IEEE Transactions on Education, vol.48, no.2, pp. 248- 253, May 2005.

[7] Frieze, C. "The images of computing: engaging undergraduates in the broad issues of computer science," Proceedings of the 42nd ACM technical symposium on Computer science education (SIGCSE '11). ACM, New York, NY, USA, 565-570.

[8] Goggin, G. Mobile Phone Culture. London. Routledge. 2008.

[9] Heersink, D., Moskal, B.M. "Measuring high school students' attitudes toward computing," Proceedings of the 41st ACM technical symposium on Computer science education (SIGCSE '10). ACM, New York, NY, USA, 446-450.
[10] Hoegh, A.; Moskal, B.M. "Examining science and engineering students' attitudes toward computer science," Frontiers in Education Conference, 2009. FIE '09. 39th IEEE, vol., no., pp.1-6, 18-21 Oct. 2009.

[11] IBM Study Finds Consumers Prefer a Mobile Device Over the PC. 2008. http://www-03.ibm.com/press/us/en/pressrelease/25737.wss

[12] Kurkovsky, S. "Engaging students through mobile game development," Proceedings of the 40th ACM technical symposium on Computer science education (SIGCSE '09). ACM, New York, NY, USA, 44-48.

[13] Ling, R. The Mobile Connection. The Cell Phone's Impact on Society. Morgan Kaufmann, 2004.

[14] McFall, R.L., DeJongh, M. "Increasing engagement and enrollment in breadth-first introductory courses using authentic computing tasks," Proceedings of the 42nd ACM technical symposium on Computer science education (SIGCSE '11). ACM, New York, NY, USA, 429434.

[15] Munson, A., Moskal, B., Harriger, A., Lauriski-Karriker, T., Heersink, D. "Computing at the high school level: Changing what teachers and students know and believe," Computers \& Education, Volume 57, Issue 2, September 2011, Pages 1836-1849.

[16] Okazaki, S., Skapa, R., Grande, I. 2008. Capturing global youth: mobile gaming in the U.S., Spain, and the Czech Republic. ComputerMediated Communication, 13 (2008), 827-855.

[17] Sarker, S., Wells, J.D. 2003. Understanding mobile handheld device use and adoption. Comm. ACM, 46, 12 (Dec. 2003), 35-40.

[18] Schulte, C., Knobelsdorf, M. “Attitudes towards computer sciencecomputing experiences as a starting point and barrier to computer science." Proceedings of the third international workshop on Computing Education Research (ICER '07). ACM, New York, NY, USA, 27-38.

[19] Thulin, E., Vilhelmson, B. "Mobiles everywhere: youth, the mobile phone, and changes in everyday practice," Nordic Journal of Youth Research, 15 (2007), 235-253.

[20] Wolz, U., Barnes, T., Bayliss, J., Cromack, J. 2009. Girls do like playing and creating games. Proc. SIGCSE (Mar. 2009), 199-200.

\section{AUTHOR INFORMATION}

Stan Kurkovsky, Professor, Department of Computer Science, Central Connecticut State University. 